\title{
Field evaluation of poor performance in Standardbred trotters
}

\author{
Emmanuelle van Erck, Vendula Jakesova, Pierre Lekeux and Tatiana Art
}

Equine Sports Medicine Centre, Equine Clinic, Faculty of Veterinary Medicine, University of Liège, Liège, Belgium

\begin{abstract}
Summary
Exercise tests allow evaluating athletic capacity and fitness, following training-induced adaptations and determining causes of poor performance. A retrospective study was conducted over the cases of 40 poor performing Standardbreds referred to an Equine Sports Medicine consultation at a Belgian racetrack. The study aimed at determining if the implementation of a standardised exercise test and determination of specific athletic parameters could discriminate between the poor performers and a group of eight healthy racehorses and help in establishing a diagnosis. After a through clinical examination, the horses were submitted to an exercise test that consisted of 3 bouts of $1500 \mathrm{~m}$ at increasing speeds with a recovery phase of $500 \mathrm{~m}$ in between. Speed and heart rate were continuously monitored and blood lactate concentrations were evaluated after each step. Pre and post-effort blood work and respiratory endoscopy with sampling were done in each horse. Five main causes of poor performance were identified: locomotor, respiratory, cardiac, muscular problems and inadequate training. In the poor performers group, 24 horses suffered from upper and/or lower respiratory disease, 20 from lameness, 4 from cardiac disease, 4 from exercise-induced myopathy and 5 from maladjusted training. More than half of the horses had multiple problems (23 horses). The fitness parameters $\left(V_{L A 4}, V_{200}\right)$ obtained were useful for inter-individual comparisons and discriminated poor performers from healthy controls, whatever the cause of the intolerance. This study confirms the high prevalence of lameness and respiratory diseases as causes of poor performance in racehorses. The field exercise tests were readily performed with minimal equipment and enabled to identify conditions which were not clearly apparent as during the clinical examination at rest. The recovery of maximum information by a thorough questioning of the trainer and selected ancillary examinations was critical to reach a diagnosis.
\end{abstract}

Keywords: Exercise test, athletic capacity, poor performance, lameness, respiratory disease

\section{Poor performance-Feldtest bei Trabern}

Leistungstests beim Pferd erlauben die Untersuchung von Kondition und Fitness, das Verfolgen trainingsinduzierter Anpassungen und die Erkennung von Ursachen für verminderte Leistung. Standardisierte Leistungs-Feldtests können beim Pferd mit minimalem technischem Aufwand durchgeführt werden und ermöglichen die Berechnung von Leistungsparametern, die Pferde gleichen Alters und gleicher Leistungsklasse objektiv vergleichbar machen. Anhand von 40 Trabern mit verminderter Leistung, die an ein sportmedizinisches Zentrum an einer Rennbahn in Belgien überweisen wurden, konnte die vorliegende retrospektive Studie durchgeführt werden. Es sollte untersucht werden, ob ein standardisiertes Testprotokoll und die Bestimmung spezifischer Leistungsparameter die Unterscheidung der Pferde mit mangelhafter Leistung von 8 gesunden Kontrollpferden ermöglichen und bei der Diagnosfindung hilfreich sind. Nach einer gründlichen klinischen Untersuchung und einem Warmup wurden die Pferde einem Leistungstest unterzogen, der aus 3 aufeinander folgenden Rennstrecken à 1.500 $\mathrm{m}$ bei 30, 35 und $42 \mathrm{~km} / \mathrm{h}$ bestand mit jeweils $500 \mathrm{~m}$ Trabintervallen zwischen jeder Rennphase. Geschwindigkeit und Herzfrequenz wurden kontinuierlich aufgezeichnet und nach jeder Belastungsphase wurde Blut zur Lakatmessung entnommen. Eine Stunde nach jedem Test wurden die Pferde systematisch einer Atemwegsendoskopie sowie der Entnahme einer Trachelspülprobe und einer BALF unterzogen. Bei Verdacht wurde eine Dopplerechokardiographie durchgeführt. Vor und nach jedem Test entnahm man Blutproben. Fünf Hauptkategorien für mangelhafte Leistung wurden erkennbar: Lahmheiten, Atemwegsprobleme, kardiale Probleme, muskuläre Probleme und unzureichendes Training. In der Gruppe der Poor performance-Pferde litten 24 Tiere an einer Atemwegserkrankung (Obere Atemwegsobstruktion, Entzündliche Atemwegserkrankuneg (IAD), Lungenbluten (EIPH) und/oder bakterielle Infektion. 20 Pferde waren lahm, 4 litten an einer Herzerkrankung, 4 an belastungsinduzierter Rhabdomyolyse und 5 an schlechter Trainingsanpassung. Mehr als die Hälfte der Pferde (23) wiesen multiple Probleme auf. 18 der 20 lahmen Pferde waren in Ruhe oder unter langsamem Trab symptomfrei. Der hier angewandte standardisierte Bahntest wurde teilweise zur Gewinnung der $V_{L_{4} 4^{-}}$und $V_{200}$-Werte eingesetzt. Diese Parameter erwiesen sich als nützlich zum Vergleich der Pferde mit sich selbst und sie schienen sensitiv genug, um Pferde mit mangelhafter Leistung von gesunden Kontrollpferden zu unterscheiden, gleich welche Ursache der Leistungsintoleranz zugrunde lag. Diese Parameter waren auch hilfeich zum objektiven Nachweis eines Konditionsverlusts bei Pferden mit unangemessenem Traingsplan. Pferde mit Lahmheitsproblemem schienen im Vergleich zur Kontrollgruppe unter Belastung höhere Herzfrequenzen zu zeigen und bei Pferden mit dynamischer Obstruktion der oberen Atemwege ergaben sich bei der letzten Belastungsstufe erhöhte Laktatwerte. Obwohl die Studie auf überwiesenen Fällen beruht und die Ursachen für Poor Performance in der Praxis nicht wirklich reflektiert, zeigt sie die hohe Prävalenz von Lahmheiten und Atemwegserkrankungen als Ursache für verminderte Leistung. Die Untersuchung von Trabern mit verminderter Leistung mittels des hier vorgestellten Leistungstests ermöglicht die Erkennung von Ursachen, die bei der initialen klinischen Untersuchung in Ruhe nicht klar als Gründe für die schlechte Leistungsbereitschaft erkennbar waren. Entscheidend für die Diagnosestellung waren ein Maximum an anamnestischer Information durch intensive Befragung der Trainer sowie die Durchführung ausgewählter ergänzender Untersuchungen.

Schlüsselwörter: Leistungstest, Kondition, Poor Performance, Lahmheit, Atemwegserkrankung

\section{Introduction}

Exercise testing in human sports medicine is a standard method for the evaluation of exercise capacity in human athletes. Horses are exceptional athletes, but surprisingly exerci- se testing is less common in that species and sooner performed in research facilities. This could be because these tests are considered time consuming or cumbersome to put into practise. 
Exercise testing in horses was initially developed in Sweden during the late 60's in Standardbred horses (Persson 1967) and has since been applied to study and evaluate the components of the extraordinary physiology of equine athletes during effort. Exercise tests allow evaluating athletic capacity and fitness, to follow training-induced adaptations (Seeherman and Morris 1990, Art and Lekeux 1993, Ohmura et al. 2002), and to help determine causes of poor performance (Martin et al. 2000). Sport horses referred for poor or decreased performance seldom display obvious symptoms at rest. Examination of these horses during exercise can allow eliciting clinical symptoms (Morris and Seeherman 1991, Martin et al. 2000).

The exercise tests in horses can be performed either on a track or on a treadmill. The advantages of track testing are that it is performed in a horse's natural environment and that it reflects more accurately the conditions encountered during competition. It is therefore considered as less stressful than running on a treadmill and perhaps more demonstrative of the horse's natural aptitude. Field tests can be readily performed in horses with minimal equipment (Couroucé et al. 2002). The disadvantages of performing a field exercise test are that the conditions are less standardised and perhaps more problematic to interpret, reproduce and compare.

Treadmill tests, on the other hand, are performed in a laboratory and can be accurately standardised. The speed, incline and duration of each step of the test can be specifically set and repeated. Some procedures such as exercising videoendoscopy, measurement of ventilatory parameters and arterial blood sampling, are more readily performed with the horse exercising on a treadmill. However the downsides are that an effort produced on a treadmill is less strenuous than in the field (Sloet van Oldruitenborgh-Oosterbaan and Barneveld 1995) and that it ideally requires prior acclimatation (King et al. 1995). In addition, the horse's locomotion is different on a treadmill (Barrey et al. 1993) and the weight bearing of the rider or the sulky is absent (Gottlieb-Vedi and Lindholm 1997). Thus a treadmill test cannot reproduce authentically a horse's natural effort and may not accurately reflect a horse's exercise capacity in field conditions. Treadmill tests results should be interpreted bearing these elements in mind (Couroucé et al. 1999, Sloet van Oldruitenborgh-Oosterbaan and Clayton 1999).

The Equine Sports Medicine Centre of the University of Liège has developed a referral consultation at the Wallonia racetrack. Sport horses are referred for either fitness evaluation or poor performance. A retrospective study was conducted over the cases of 40 poor performing Standardbreds. This article focuses on the implementation of standardised field exercise testing in the investigation of the causes of poor performance. Standardised field exercise tests enable the calculation of athletic parameters which can allow an objective comparison between horses of similar age and competitive category (Rose et al. 1990, Harkins et al. 1993, Couroucé et al. 2002). The study aimed at determining if a standardised exercise testing protocol and the determination of specific athletic parameters could discriminate between healthy and poor performing horses and help in establishing a diagnosis.

\section{Material and methods}

\section{Horses}

40 Standardbred trotters aged from 3 to 7 years old (12 mares, 22 geldings, 6 stallions) were included in the study. All horses were referred to the Equine Sports Medicine Centre for poor performance. A group of 8 performing Standardbred horses, aged from 3 to 6 years old and with neither a history of problems nor significant elements during the clinical examination and complementary examinations was used as a control group. All horses had been in training for over 18 months and had been qualified to race and/or raced regularly.

\section{Examination procedure}

History

A detailed questionnaire of the horse's history, training regimen and previous performances was reviewed with the owner or trainer. This allowed estimating the horse's level of training and performances, which represents crucial information for a correct interpretation of the data collected during the test.

Regarding performances, some of the questions asked were: Speed at qualifications? Over what distance? Record speed? Over what distance? Number of races run? Number of races won? Earnings?

Regarding training, trainers were asked to detail the horse's work over a week. What type of work is done each day? Over what distance? During what time? Over what type of ground? Is the horse out at pasture during the day? Etc. The horse's medical history also brought forward essential elements.

\section{Clinical examination}

As for any thorough clinical examination, care was taken to perform the cardiac auscultation over several minutes and on both sides of the chest to assess the presence of arrythmias or murmurs. Respiratory examination comprised the auscultation of the trachea, bronchi and both lung areas. The horse's limbs, back and muscular masses were carefully examined and palpated. The horses performed the exercise test on the track only if they were judged sound and fit enough

\section{Field exercise test}

\section{Exercise test}

The exercise test was performed at the Wallonia racetrack (Ghlin, Belgium). The trotting track is a flat, well drained track of $1000 \mathrm{~m}$. The test consisted in an initial warm-up phase at a slow trot $(20 \mathrm{~km} / \mathrm{h})$ over $3000 \mathrm{~m}$. The horse then ran 3 bouts of $1500 \mathrm{~m}$ at 30,35 and $42 \mathrm{~km} / \mathrm{h}$ with a recovery phase of $500 \mathrm{~m}$ at a slow trot between each phase. At the end of the last step, the horses recovered by a trotting slowly once around the track and returned walking to the stables located approximately $300 \mathrm{~m}$ from the track. The horses were systematically submitted to an endoscopical examination of the airways one hour after the exercise test. If respiratory noise 
was heard during the test, the horse was also scoped immediately after returning from the track.

\section{Equipment}

Speed and heart rate were continuously monitored using a GPS system coupled to a heart-rate meter (Equipilot $\left.{ }^{\circledR}, 1\right)$. Values were controlled with a chronometer and an ECG telemetry unit (Lifescope $\left.{ }^{\circledR},{ }^{2}\right)$ respectively. One minute after the end of each bout, a blood sample was taken to evaluate blood lactate concentrations with a portable system (Accusport $\left.^{\circledR}, 3\right)$.

\section{Measured parameters}

Heart rate and blood lactate concentrations were plotted against speed. Parameters of $\mathrm{V}_{\mathrm{LA} 4}$ (speed at which lactatemia was equal to $4 \mathrm{mmol} / \mathrm{l}$ ) and $\mathrm{V}_{200}$ (speed at which heart rate was equal to $200 \mathrm{bpm}$ ) were calculated by linear interpolation and used for intra and inter-individual comparison. A Mann-Whitney statistical test was used for the comparison of the parameters between the control and the poor performer groups. Differences were considered as significant when $\mathrm{P}<0.05$.

\section{Complementary examinations}

\section{Blood samples}

A blood sample was systematically taken to evaluate haematology and basic plasma biochemistry. The activity of muscular enzymes (AST, LDH, CPK) before and one hour after exercise (CPK) was done to detect possible exertional rhabdomyolysis. Indicators of oxidative stress were also determined, but the presentation of these results is beyond the scope of this study.

\section{Airway endoscopy}

Upper airway endoscopy was performed after exercise without sedation. Arythenoid symmetry and movement were assessed and scored after eliciting hyperventilation by obstructing both nares (Archer et al. 1991, Dixon et al. 2003). Pharyngeal lymphoid hyperplasia was graded from 1 to 4 and nasopharyngeal stability was appreciated during hyperventilation.

The horses were then sedated with romifidine (Sedivet $\left.{ }^{\circledR}, 4\right)$. Tracheal mucus was scored according to a published 5 score system (Gerber et al. 2004). A tracheal wash (TW) was done by instillation $30 \mathrm{ml}$ of sterile saline through a guarded catheter placed in the operating canal of the endoscope. The endoscope was then wedged into a caudo-dorsal bronchi to perform a broncho-alveolar lavage (BAL). The BAL consisted in the instillation of $250 \mathrm{ml}$ of sterile saline. Two $50 \mathrm{ml}$ aliquots were initially instillated and retrieved followed by 3 aliquots of $50 \mathrm{ml}$ which were individually instillated and retrieved one after the other. Both samples were submitted to a cytological analysis. The tracheal wash was also sent for a bacteriological analysis. Guttural pouch endoscopy was performed subsequently if indicated.

\section{Doppler echocardiography}

When a pathological heart murmur of a grade $>3$ out of 6 was auscultated (Young and Wood 2000), a Doppler echocardiography was undertaken after a post-exercise recovery period, sufficiently long to allow a return to resting heart rate values. Cardiac morphology was estimated by standard twodimensional longitudinal and transversal views. The $M$-mode was used to measure ventricular cavity and wall dimensions. Colour and pulsed Doppler were used to examine blood flow through the aortic, pulmonary, mitral and tricuspid valves.

\section{Definition of the diagnosed problems}

Five main categories of problems were identified as causes of poor performance: locomotor, respiratory, cardiac, muscular problems and inadequate training.

\section{Locomotor problems}

Horses were identified as having locomotor problems when they showed signs of lameness during walk, warm-up trot or at any step of the exercise test.

\section{Muscular problems}

Muscular problems were defined as post-exercise myopathy and characterised by at least doubled post-exercise CK levels in comparison to normal resting values.

Respiratory problems

\section{Respiratory problems}

Respiratory problems were divided into upper and lower airway problems. Presence of pharyngitis was noted but not considered as a pathological entity in itself. Horses were considered as having upper airway problems when a dynamic obstruction was observed during transient induced hyperventilation of the post-exercise endoscopy (performed without sedation).

Lower respiratory problems were identified as: Inflammatory airway disease (IAD), when inflammatory cell populations were increased in the BAL (neutrophils > 10\% and/or eosinophils $>2 \%$ and/or mastocytes $>2 \%$ ), Exercise-induced pulmonary haemorrhage (EIPH), when more than 5 red blood cells and 5 haemosiderophages were observed per microscopic field (x100). Episodes of EIPH were considered as recurrent when the haemosiderophages were at various stages of differentiation and bacterial respiratory infection when several of the following elements were observed: observation of tracheal mucus, bacterial growth of a pathogenic species in the TW, observation of bacteria outside and inside the cytoplasm.

\section{Cardiac problems}

Horses were considered as having cardiac problems when they had one or several of the following: Pathological arrhyth- 
mias at rest or during exercise, one or several moderate to severe valvular insufficiencies as determined by an echocardiography-Doppler examination.

\section{Inappropriate training}

Inappropriate training was considered as a cause of poor performance when the level of a weekly training regimen seemed insufficient, when both $V_{200}$ and $V_{\text {LA4 }}$ were inferior to the range determined in the control group and when no obvious clinical elements were found.

\section{Results}

The horses of the healthy control group were performing racehorses that had neither a history of problems nor significant elements during the clinical examination and complementary examinations. Upon auscultation, 5/ 8 horses had a grade 1 to 2 left or right-sided systolic murmurs. Four horses had a few haemosiderophages ( $<5$ per field) in their BAL fluid but none of them had either post-effort red blood cells or signs of inflammation, as described above. Therefore EIPH was not considered as a significant element in that group.

All poor performers had one or several problems revealed by the field and complementary examination procedures. In the poor performers group, 24 horses suffered from respiratory disease, 20 from lameness, 4 from cardiac disease, 4 from exercise-induced rhabdomyolysis and 5 from maladjusted training. More than half of the horses had multiple problems (23 horses).

Apart from increased muscular enzyme activity in the horses with rhabdomyolysis, the haematology and blood biochemistry analysis in both groups did not reveal any significant elements.

\section{Diagnosed problems}

Locomotor problems

Of the 20 cases of lameness, 18 were absent during the initial examination and obvious only during the exercise test. Eleven horses were normal during the warm-up and first phase of the test but showed lameness only at higher speeds. Lame horses had higher heart rates in comparison to the control group and $V_{200}$ consequently significantly lower. The horses were subsequently referred to their regular veterinarian for the investigation of the underlying cause(s) of their lameness.

Muscular problems

Four horses had CK levels above $650 \mathrm{UI} / \mathrm{I}$ and two of them had also increased levels of AST and LDH. Myopathy was associated with lameness in 3/4 cases.

\section{Respiratory problems}

The upper airway problems were dynamic obstruction during exercise caused by: recurrent laryngeal neuropathy $(n=1)$, dorsal displacement of the soft palate (DDSP; $n=4)$, epiglottic retroversion $(n=1)$. All these horses made a respiratory noise during the exercise test, although the trainers were unaware having heard the horses making noise in 3 of the 4 DDSP cases.

In the lower respiratory problems, we diagnosed: IAD in $13 / 24$ horses, EIPH in 10/24 horses, bacterial respiratory infection in 13/24 horses. The following species were considered as pathogenic: Lancefield type C beta-haemolytic Streptococci, Klebsiella pneumoniae and Pasteurella sp.

Auscultation of crackles in the trachea was a sensitive marker of airway disease. The association between IAD, bacterial infection and EIPH was frequent although not systematic. Seven horses with IAD had concurrent EIPH and five had concurrent respiratory infection. None of the horses referred had signs of viral infection.

\section{Cardiac problems}

Pathological arrhythmias diagnosed were atrial fibrillation $(n=1)$ and frequent ventricular premature complexes $(n=1)$. Two horses had several moderate to severe valvular insufficiencies as determined by the echocardiography-Doppler examination $(n=2)$. One horse had a severe tricuspid valve insufficiency that induced post-exercise ventral oedema and another had a moderate mitral valve reflux with signs of ventricular hypertrophy and a reduced shortening fraction.

\section{Inappropriate training}

Inappropriate training was considered as a cause of poor performance in 5 horses. These horses were all under the age of 3 years old and belonged to amateur trainers. They were housed indoors and did not have access to a pasture or a paddock. The horses were submitted twice a week to speed training sessions and were either walked or trotted over short distances (max. $5 \mathrm{~km}$ ) the other days. The diagnosis of "inappropriate training" was confirmed in $3 / 5$ horses, when reexamined 6 weeks later, they showed a marked improvement of their parameters after an increase in their training level was undertaken.

\section{Outcome of the exercise tests}

The standardised exercise test enabled all horses to reach or exceed a lactatemia of $4 \mathrm{mmol} / \mathrm{l}$ and a heart rate of 200 bpm. However, two horses were stopped after the second step of the test because of an aggravating lameness.

The athletic parameters of $V_{L A 4}$ and $V_{200}$ were generally significantly lower in the poor performers compared to the healthy control horses, whatever the cause of the intolerance. For each horse, the diagnosed problems were ranked according to their importance in generating poor performance. Figure 1 indicates the results of $V_{L A 4}$ and $V_{200}$ in horses for which the indicated diagnosis was the main origin of poor performan$c e$, and compares them to the values obtained in the control group. 
Horses suffering from lameness tended to have higher heart rates during the exercise test in comparison to the control group, a phenomenon that decreased their $V_{200}$ more than their $V_{\text {LA4 }}$.

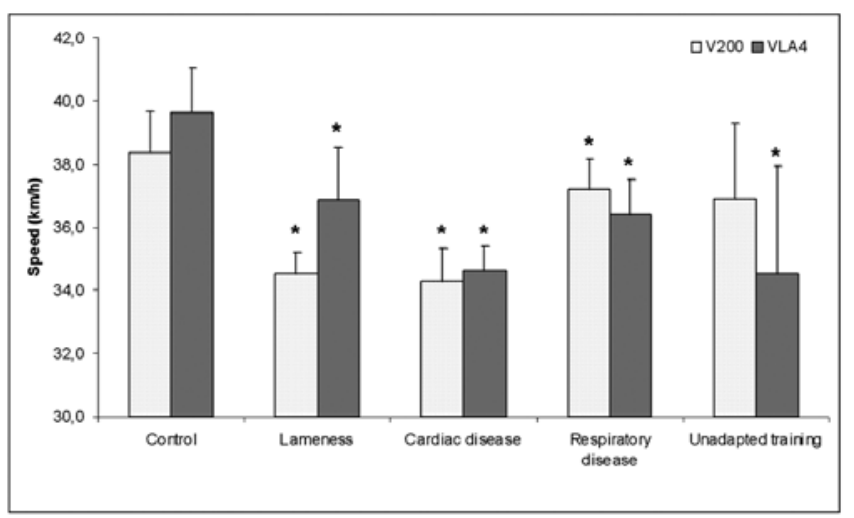

Fig 1 Values (A) of $\mathrm{V}_{\mathrm{LA} 4}$ (speed at which lactatemia was equal to 4 $\mathrm{mmol} / \mathrm{I}$ ) and (B) of $\mathrm{V}_{200}$ (speed at which heart rate was equal to 200 bpm) in 40 poor performing Standardbreds suffering from lameness, respiratory or cardiac disease or unadapted training compared to values obtained from a healthy control group of 8 performing Standardbreds. $\left.{ }^{*}\right)$ indicates a significant difference from control.

Messwerte (A) der $V_{\text {LA4 }}$ (Geschwindigkeit bei Laktatwert $4 \mathrm{mmol} / \mathrm{l}$ ) und (B) der $V_{200}$ (Geschwindigkeit bei Herzfrequenz 200/min) von 40 Trabern mit verminderter Leistungsfähigkeit, die an Lahmheiten, Atemwegs- oder Herzerkrankungen litten, im Vergleich zu Werten 8 gesunder und im Rennbetrieb stehender Traber. ${ }^{*}$ ) zeigt einen signifikanten Unterschied zur Kontrolle.

The horse suffering from dynamic upper airway obstruction had a dramatic increase in lactatemia after the last step of the exercise. Figure 2 shows a typical evolution of lactatemia with speed in a horse with dorsal displacement of the soft palate. Lower airway problems also had a tendency to affect more markedly blood lactate concentrations in comparison to heart rate, but less severely than for upper airway obstructive diseases.

Inappropriate training also had a significant effect on the measured fitness parameters, but because this was based on a more subjective appreciation, the variability of the results was greater in that group.

\section{Discussion}

Maximum collection of information, by thorough questioning of the trainer or owner, helped to appreciate the level of training and performance of the horse before the exercise test and to adapt interpretation of results to each horse. Although care was taken to obtain homogeneous groups and compare horses with similar levels of performance, the number of horses included in this study was insufficient to distribute them into categories taking into account age and objective indicators of performance (earnings, racing times...). A larger scale study would allow such ranking and result in more pertinent inter-individual comparisons as well as to encompass other problems. Because this study was based on referred cases, it might not truly reflect the ordinary causes of poor performance encountered in practise in Standardbred racehorses. However, it corroborates previous publications by demonstrating the high prevalence of lameness and respiratory diseases as causes of poor performance in competition horses (Morris and Seeherman 1991, Martin et al. 2000).

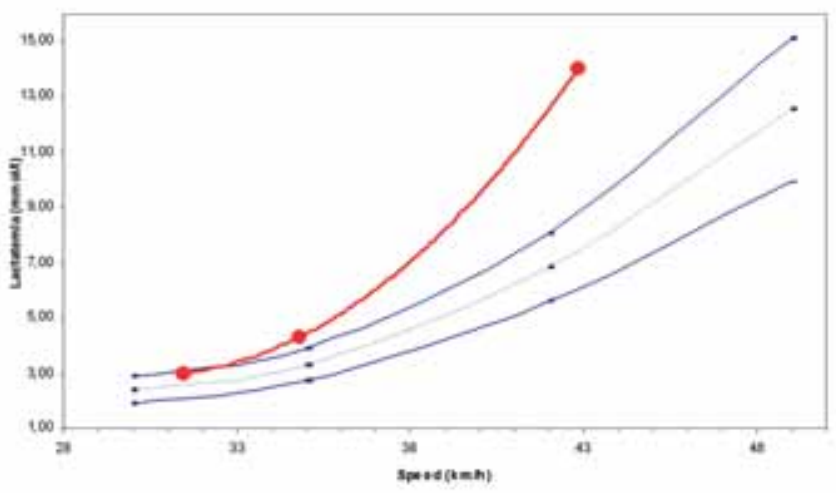

Fig 2 Representation of blood lactate concentrations according to speed in a poor performing Standardbred with dorsal displacement of the soft palate at the third step of the track exercise test (red line) and comparison with the mean (dotted blue line) and upper and lower $95 \%$ confidence interval values (continuous blue lines) in the control group.

Darstellung der Blutlaktatkonzentrationen relativ zur Geschwindigkeit bei einem Traber mit mangelhafter Leistung und Gaumensegelverlagerung unter der 3. Teststufe (rote Linie) im Vergleich zu den mittleren (blau gepunktet), oberen und unteren Referenzwerten (blave Linien) der Kontrollgruppe.

The cases were generally referred because conventional examinations had failed to bring forth abnormalities. The veterinarians had often performed a complete blood work analysis before referring the horses at the Equine Sports Medicine Centre that indicated parameters in the normal range. The examination of poor performing Standardbred racehorses by the proposed exercise test in the field enabled to identify conditions which were not clearly apparent as causes of poor performance during the initial clinical resting examination. The stepwise test was preferred to a maximal exertion test to allow a progressive fatigue of the horse and to avoid aggravating underlying injuries. The standardised track test was adapted from previously published data (Couroucé et al. 1997). It was also indicated to estimate fitness parameters such as $V_{\text {LA4 }}$ and $V_{200}$. The complementary examinations were essential to reach a definitive diagnosis. The methods described were chosen to investigate the widest possible range of subclinical problems causing poor performance. These methods were also chosen because they were readily available and could be performed in one-day outpatients. A gastroscopy was carried out in some of the cases were the history was evocative of gastric ulcers. The implication of gastric ulcers in poor performance remains unclear and their prevalence is high even in performing racehorses. Systematic gastroscopy is therefore arguable. Other areas, such as nutrition, could also perhaps be investigated.

The fitness parameters were useful to compare horses between themselves and seemed sensitive enough to discriminate poor performers from the healthy controls (Rose et al. 1990, Couroucé et al.1997). They were also helpful to objectively demonstrate a lack of fitness in horses with an inadequate training regimen. The latter were young ( 2 to 3 years old) trotters that had a predominance of fast intensive work 
and lacked in "endurance" training, such as one obtained by jogging at a moderate speed over several kilometres or staying out in pasture. Three of the 5 cases were re-examined on the track 6 weeks after the initial test and performed an identical standardised effort. Results showed a marked improvement of their $V_{L A 4}$ and $V_{200}$ parameters after following a modified training scheme. Regular exercise testing thus constitutes an interesting means of assessing the evolution of the horses' physical condition induced by training and can help to adapt more rapidly an inadequate workload (Couroucé 1999).

The horses suffering from lameness had globally higher heart rates in comparison to the control group. The pain generated from the lameness could be responsible for the increased heart rates during effort. The assessment of $V_{200}$ alone did not appropriately reflect this phenomenon and the analysis of each individual graph plotting heart rates against speed made it more obvious. As no abnormalities were found during the basic examination at walk and trot, examining the horses during the exercise test at higher speeds was essential to establish a diagnosis in 18/20 cases. Because the horses were referred back to their veterinarians, no record of their underlying cause of lameness was subsequently obtained. Three horses had episodes of exercise-induced rhabdomyolysis or "tying-up" that could have been secondary to the lameness. These horses had a history of strained breathing during or post exercise rather than one of abnormal gait.

Cardiac murmurs were common findings in both the control and principal groups (Kriz et al. 2000). In racehorses, training and competition results in cardiac hypertrophy and often results in secondary valvular reflux (Buhl et al. 2005). The cardiac problems diagnosed here were considered as causes of poor performance as they altered the horse's cardiac function and/or morphology, as assessed by the echocardiographic Doppler examination. As expected, these problems resulted in higher heart rates during the exercise tests. Atrial fibrillation was responsible for tachycardia and was the condition which altered most dramatically heart rate. In all cardiac cases, post-exercise cardio-respiratory recovery was prolonged.

Out of the 40 horses examined in the principal group, 27 had at least one of the respiratory conditions defined. Upper airway endoscopy and TW and BAL samples were essential complementary exams to reach a diagnosis in these horses. Because respiration is the physiological limiting factor to maximal performance in healthy equine athletes (Wagner et al. 1989, Art et al. 1993), the occurrence of respiratory disease impedes their potential to reach maximal performance (Covetil and Denicola 1999). Investigating the presence of airway disease, even when its evolution is subclinical, is a crucial step that cannot be overlooked when examining a poor performer.

During the exercise test, respiratory disease generally influenced lactatemia more markedly than heart rates. Upper airway obstruction, when it occurred, resulted in a more substantial increase in blood lactate concentrations. In 5 out of 6 cases, upper airway obstruction cases displayed concomitant lower airway disease. Lower VLA4 could result from a more rapid onset of the anaerobic lactic metabolic pathway in horses with impaired gas exchange. Horses with even subclinical inflammatory conditions such as IAD or EIPH have been shown to demonstrate an aggravated hypoxemia during high-intensity exercise (Covetil and Denicola 1999).

In practise, it is often challenging to diagnose upper airway dynamic obstructions by resting endoscopy. In this study, the horses with upper airway problems showed dynamic obstruction immediately after exercise under moderate induced hyperventilation. Dynamic obstruction was more readily produced after the horses had exercised, probably due to upper airway muscular fatigue, which rendered the nasopharynx and/or larynx more unstable. The history or presence of a respiratory noise during effort was important in establishing the diagnosis. Video-endoscopy during a treadmill exercise remains a gold standard to confirm a diagnosis of upper airway obstruction. The dynamic alterations in upper airway patency may be correctly defined and characterised, which is essential for taking a decision when a surgical option is at stake.

Lower airway diseases were predominant in the cases examined in this study. Performing both a TW and a BAL was necessary as both sample brought forth distinct information. For instance, horses with bacterial infection usually had a TW cytology of poor quality, which prohibited satisfactory differential cell count. Some horses were diagnosed with IAD based solely on the BAL fluid cytology as the TW sample was normal.

The high prevalence of respiratory cases could be due to housing, training conditions, transportation and mingling during competitions, which contribute to the development of low grade inflammation in racehorses. Inflammation can be maintained or further increased when horses sustain training and strenuous work (Newton and Wood 2002). The veterinarian plays an important role in advising owners and trainers of ways to improve stable management. Advice should include means of controlling potential sources of dust in the horse's environment, reducing infectious pressure by vaccination, proper stable cleaning and limitation of inter-individual contacts.

After their field examination at the Equine Sports Medicine Centre, the horses were referred back to their veterinarians with therapeutic suggestions. Our deontological policy is to leave further investigation of an established lameness to the referring veterinarian. A re-examination is proposed 4 to 6 weeks later but the final decision is left to the appreciation of the practitioner, owner and/or trainer. In all cases, attempt is made to assess the evolution of a case by contacting the person responsible for the horse after a normal training has been resumed. Our future aim is to assure a regular follow-up of the referred cases by systematic sequential exercise testing.

To conclude, field exercise tests represent an interesting tool for the determination of causes of poor performance in horses that are clinically normal at rest. It requires minimal equipment and is readily performed on a track. The recovery of a maximum of elements obtained by a thorough questioning of the trainer and by selected ancillary examinations is critical to reach a diagnosis. The analysis of athletic indices also contributes to orienting the diagnosis and allows a longterm follow-up of training or recovery from disease. Through a global approach, such as the one proposed in this study, it is possible to bring fore respiratory, cardiac, musculoskeletal 
or even training management problems, which all to various degrees act to impair the horse's performance. These tests can be adapted to other types of disciplines. Treadmill examination remains an essential complementary tool in some circumstances.

\section{Manufacturer's addresses}

1 Equipilot ${ }^{\circledR}$, Fidelak, Germany

2 Lifescope ${ }^{\circledR}$, Nihon Kohden, USA

${ }^{3}$ Accusport $^{\circledR}$, Boehringer, Germany

${ }^{4}$ Sedivet $^{\circledR}$, Boehringer Ingelheim, Germany

\section{Literature}

Archer R. M., Lindsay W. A. and Duncan I. D. (1991): A comparison of techniques to enhance the evaluation of equine laryngeal function. Equine Vet J 23, 104-107

Art T. and Lekeux P. (1993): Training-induced modifications in cardiorespiratory and ventilatory measurements in thoroughbred horses. Equine Vet J 25, 532-536

Barrey E., Galloux P., Valette J. P., Auvinet B. and Wolter R. (1993): Stride characteristics of overground versus treadmill locomotion in the saddle horse. Acta Anat (Basel) 146, 90-94

Buhl R., Ersboll A. K., Eriksen L. and Koch J. (2005): Use of color Doppler echocardiography to assess the development of valvular regurgitation in Standardbred trotters. J Am Vet Med Assoc. $227,1630-1635$

Covetil L. and Denicola D. (1999): Blood gas, plasma lactate and bronchoalveolar lavage cytology analyses in racehorses with respiratory disease. Equine Vet J Suppl. 30, 77-82

Couroucé A. (1999): Field exercise testing for assessing fitness in French standardbred trotters. Vet J. 157, 112-122

Couroucé A., Geffroy O., Barrey E., Auvinet B. and Rose R. J. (1999): Comparison of exercise tests in French trotters under training track, racetrack and treadmill conditions. Equine Vet J Suppl. 30, 528-532

Couroucé A., Chretien M. and Valette J. P. (2002): Physiological variables measured under field conditions according to age and state of training in French Trotters. Equine Vet J 34, 91-97

Couroucé A., Chatard J. C. and Auvinet B. (1997): Estimation of performance potential of standardbred trotters from blood lactate concentrations measured in field conditions. Equine Vet J. 29, 365-369

Gerber V., Straub R., Marti E., Hauptman J., Herholz C., King M., Imhof A., Tahon L. and Robinson N. E. (2004) Endoscopic scoring of mucus quantity and quality: observer and horse variance and relationship to inflammation, mucus viscoelasticity and volume. Equine Vet J 36, 576-582

Gottlieb-Vedi M. and Lindholm A. (1997): Comparison of standardbred trotters exercising on a treadmill and a race track with identical draught resistances. Vet Rec 140, 525-528
Harkins J. D., Beadle R. E. and Kamerling S. G. (1993): The correlation of running ability and physiological variables in thoroughbred racehorses. Equine Vet J 25, 53-60

King C. M., Evans D. L. and Rose R. J. (1995): Acclimation to treadmill exercise. Equine Vet J Suppl 18, 453-456

Kriz N. G., Hodgson D. R. and Rose R. J. (2000): Prevalence and clinical importance of heart murmurs in racehorses. J Am Vet Med Assoc. 216, 1441-1445

Martin B. B. Jr, Reef V. B., Parente E. J. and Sage A. D. (2000): Causes of poor performance of horses during training, racing, or showing: 348 cases (1992-1996). J Am Vet Med Assoc 216, 554 558

Morris E. A. and Seeherman H. J. (1991): Clinical evaluation of poor performance in the racehorse: the results of 275 evaluations. Equine Vet J 23, 169-174

Newton J. and Wood J. (2002): Evidence of an association between inflammatory airway disease and EIPH in young Thoroughbreds during training. Equine Vet J Suppl. 34, 417-424

Ohmura H., Hiraga A., Matsui A., Aida H., Inove Y., Asai Y. and Jones J. H. (2002): Physiological responses of young Thoroughbreds during their first year of race training. Equine Vet J Suppl 34 140-146

Rakestraw P., Hackett R., Ducharme N., Nielan G and Erb H. (1991): Arytenoid cartilage movement in resting and exercising horses. Vet Surg 20, 122-127

Rose R. J., Hendrickson D. K. and Knight P. K. (1990): Clinical exercise testing in the normal thoroughbred racehorse. Aust Vet J 67 345-348

Seeherman H. J. and Morris E. A. (1990): Application of a standardised treadmill exercise test for clinical evaluation of fitness in 10 thoroughbred racehorses. Equine Vet J Suppl 9, 26-34

Sloet van Oldruitenborgh-Oosterbaan M. M. and Barneveld A (1995): Comparison of the workload of Dutch warmblood horses ridden normally and on a treadmill. Vet Rec 137, 136-139

Sloet van Oldruitenborgh-Oosterbaan M. M. and Clayłon H. M. (1999): Advantages and disadvantages of track vs. treadmill tests. Equine Vet J Suppl 30, 645-647

Young L. and Wood J. (2000): Effect of age and training on murmurs of atrioventricular valvular regurgitation in young thoroughbreds. Equine Vet J 32, 195-919

Wagner P., Gillespie J., Landgren G, Fedde M., Jones B., DeBowes R., Pieschl R. and Erickson H. (1989): Mechanisms of exerciseinduced hypoxemia in horses. J Appl Physiol 66, 1227-1233

Emmanuelle van Erck, DVM, PhD

Equine Sports Medicine Centre

Equine Clinic, B4 1

Faculty of Veterinary Medicine

University of Liège

Sart Tilman

4000 Liège

Belgium

emmanuelle.vanerck@skynet.be

Pferdeheilkunde Curriculum Berlin

Reproduktion

9.-10. Dezember 2006

Harald Sieme und Heinz Adolf Schoon

Berlin-Brandenburgische Akademie der Wissenschaften

www.humboldt-curricula.com 